\title{
Design of a Prototype of Smoke Exhaust Control System in an Enclosed Room with the Fuzzy Sugeno Method
}

\section{Perancangan Prototipe Sistem Kendali Pembuang Asap Pada Ruangan Tertutup dengan Metode Fuzzy Sugeno}

\author{
Setya Ardhi $\left.{ }^{1 *}\right)$, Danny Cahya Kusuma ${ }^{2}$, Judi Prajetno Sugiono ${ }^{3}$, Suhatati Tjandra ${ }^{4}$ \\ \{setyaardhi@stts.edu ${ }^{1}$, danny.cahya.kusuma@gmail.com ${ }^{2}$,jpsugiono@stts.edu ${ }^{3}$, tati@ stts.edu ${ }^{4}$ \}
}

Institut Sains Dan Teknologi Terpadu Surabaya (ISTTS), Surabaya, Jl. Ngagel Jaya Tengah 73-77 Surabaya ${ }^{1,2,3,4}$

\begin{abstract}
Cigarette smoke can contaminate indoor air that causes some health risks. Smoke control in enclosed rooms is necessary to reduce the thick smoke in them by controlling the CO content index to the desired point. The purpose of the study, knowing the grouping of the density of smoke and the time in disposing of smoke to the point of a predetermined setpoint value of 60 ppm. This research applied the Fuzzy Logic Sugeno Method and hardware design using a prototype in the form of an acrylic box with a ratio of 1:10 of the actual size as a tool test site; LCD to display information, namely, in the form of smoke density, fan, setpoint value, and smoke value; MQ2 sensors for CO smoke detection; Arduino Nano as a microcontroller; and relay and fan as output. The experiment results resulted in 3 categories of smoke: low, medium, and high. Besides, the results of this study also showed that the time required to emit smoke in a closed room to the point of a setpoint value of 60 ppm with the help of 3 fans on each fan $12 \mathrm{v} / 0.14 \mathrm{~A}$ is 2 minutes 05 seconds.
\end{abstract}

Keywords - EnClosed room, Fuzzy Logic Sugeno Method, Cigarette Smoke

\begin{abstract}
Abstrak. Asap rokok dapat mencemari udara dalam ruangan yang menyebabkan beberapa risiko kesehatan. Pengendalian asap di ruangan tertutup diperlukan untuk mengurangi asap tebal di dalamnya dengan cara mengontrol indeks kandungan CO ke titik yang diinginkan. Tujuan penelitian, mengetahui pengelompokan massa jenis asap dan waktu pembuangan asap dengan nilai setpoint yang telah ditentukan sebesar 60 ppm. Penelitian ini menerapkan Metode Fuzzy Logic Sugeno dan perancangan perangkat keras menggunakan prototipe berupa kotak akrilik dengan perbandingan ukuran sebenarnya 1:10 sebagai alat uji lokasi; tampilan untuk menampilkan informasi berupa kepadatan asap, kipas angin, nilai setpoint, dan nilai asap; sensor MQ2 untuk deteksi asap CO; Arduino Nano sebagai mikrokontroler; dan relay dan fan sebagai output. Hasil percobaan menghasilkan 3 kategori asap yaitu rendah, sedang, dan tinggi. Selain itu hasil penelitian ini juga menunjukkan bahwa waktu yang dibutuhkan untuk mengeluarkan asap dalam ruangan tertutup dengan nilai setpoint sebesar 60 ppm dengan bantuan 3 buah fan pada setiap fan 12 v/0.14A adalah 2 menit 05 detik.
\end{abstract}

Kata Kunci - Asap Rokok, Fuzzy Sugeno, Ruangan Tertutup

\section{Pendahuluan}

Kesehatan merupakan kondisi dimana kemampuan fisik, mental, dan sosial yang baik dan lengkap dalam fungsinya serta bukan hanya tidak adanya kelemahan atau penyakit[7]. Setiap manusia ingin kehidupan yang sehat jiwa dan jasmani, tetapi dengan kemajuan waktu dan teknologi sering dijumpai berbagai penyakit serta gangguan kesehatan. Kebiasaan Merokok merupakan salah satu bagian dari pola hidup yang tidak benar, dimana dilakukan masyarakat baik orang tua maupun muda bahkan serta banyak wanita juga ikut mengkonsumsi rokok [2]. Sekarang banyak area fasilitas publik menyediakan suatu tempat ruang khusus untuk para perokok aktif [1]. Tempat ruang khusus tersebut akan terpakai setiap hari selama fasilitas umum ini buka dan akan digunakan oleh perokok, oleh karena itu ruangan tersebut dijaga kebersihannya dimulai dari segi sirkulasi udara/ fentilasi udara yang keluar atau masuk dalam tempat fasilitas smoking area [6]. Salah satu unsur asap rokok yang terkandung unsur yang berbahaya yaitu karbonmonoksida (CO) dimana memiliki keterikatan yang kuat dengan hemoglobin pada sel darah merah[5]. Dilansir dari Peraturan Menteri Tenaga Kerja dan Transmigrasi nomor PER.13/MEN/X/2011 mengenai Nilai Ambang Batas (NAB) Faktor Fisika dan Faktor Kimia [8] di Tempat Kerja, unsur CO pada tempat fasilitas umum memiliki nilai ambang batas sebesar $25 \mathrm{ppm}$. Dilansir dari bagan organisasi WHO (1999), batas pemaparan unsur gas CO pada manusia pada ruangan tertutup yaitu $80 \mathrm{ppm}$ selama 15 menit, 48 ppm selama 30 menit, 24 ppm selama 1 jam dan 8 ppm selama 8 jam. Salah satu usaha dalam mengatasi masalah batas kandungan udara pada ruangan tertutup diperlukan adanya sistem kontrol otomatis yang digunakan sebagai penyedot atau pembuang asap yang mengandung CO berlebihan[10]. Dari metode sistem kontrol otomatis yang tersedia pada fungsi paradigma sistem cerdas, penelitian ini akan menggunakan Fuzzy Logic Sugeno sebagai system control otomatis. Pada penelitian yang pernah dilakukan sebelumnya oleh penelitian sebelumnya[6], dimana memiliki sistem yang telah berjalan dengan baik tetapi masih 
memiliki kendala yang tidak sesuai dengan harapan yaitu dengan pengontrolan terhadap kipas pembuangan berhasil dilakukan, tetapi belum akurat dalam pengukuran konsentrasi asap yang disebabkan oleh variable serta derajat keanggotaan[9] sehingga metode tersebut masih kurang banyak dalam memberi keputusan metode tersebut dalam membuang asap. Sistem pada peniliatian diharapkan dapat membantu masyarakat untuk sistem kontrol asap ruangan perokok dengan tingkat akurasi yang tinggi yang akan digambarkan menjadi menjadi grafik keanggotaan[9].

\section{METODE}

Metode penelitian ini dimulai dengan mengambil masukan dari gas/asap rokok yang akan diterima oleh beberapa sensor, kemudian dari sensor ini akan menjadi nilai input, kemudian diproses oleh sistem kontrol berbasis algoritma Fuzzy Sugeno, kemudian hasil yang diberikan oleh sistem kontrol akan mengendalikan kipas penghisap asap yang akan sesuai dengan setpoint yang akan diinginkan. Sistem kendali pada penelitian ini dengan menerapkan Algoritma Logika Fuzzy, baik secara masukan (input) yang akan meliputi Fuzzification, rule based (basis pengetahuan), logika pengambilan keputusan (inference) dan defuzzification hingga hasil output yang terjadi [4] yang bisa dilihat pada gambar 1. Adapun dari blok diagram dari sistem kontrol fuzzy sendiri adalah sebagai berikut:

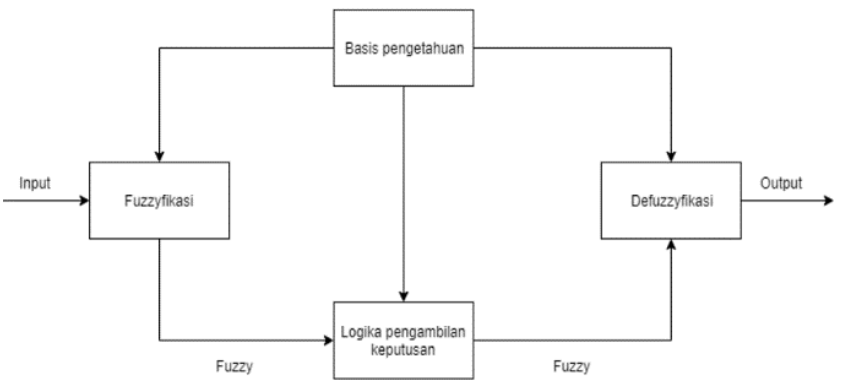

Gambar 1. Diagram sistem Fuzzy

Keempat blok terrsebut dijelaskan seperti berikut:

1. Fuzzifikasi : proses untuk membuat kuantitas yang sifatnya tegas menjadi fuzzy

2. Logika penalaran (Inference): proses implikasi dalam menalar nilai masukkan guna penentuan nilai keluaran bentuk pengambilan keputusan.

3. Rule base : aturan-aturan fuzzy yang dinyatakan dalam "if...then" yang merupakan inti dari relasi fuzzy.

4. Deffuzifikasi : mengkonversi setiap hasil dari inference engine yang diekspresikan dalam bentuk fuzzy set kesuatu bilangan real.

Dalam Metode Sugeno, proses deffuzifikasi menggunakan perhitungan Weight-Average (WA)

: $\mathrm{WA}=$ Nilai rata-rata, $\alpha \mathrm{n}=$ nilai predikat aturan ke-n, dan $\mathrm{zn}=$ indeks nilai konstanta ke-n.

$\mathrm{WA}=\left(\frac{\propto 1 * z 1+\propto 2 * z 2+\propto 3 * z 3+\cdots \propto n * z n}{z 1+z 2+z 3+\cdots+z n}\right)$

\section{A. Sistem Pengendali}

\section{Hasil dan Pembahasan}

Mengikuti metode yang diterapkan pada penelitian ini maka akan didesain sistem pengendali yang menyesuaikan algoritma yang akan hendak dipakai, maka bisa dilihat pada gambar 2 yang dimana merupakan diagram sistem pengendali. Pada gambar diagram system pengendali menggunakan 4 sensor yang dipasang paralel agar memberikan hasil yang akurat.

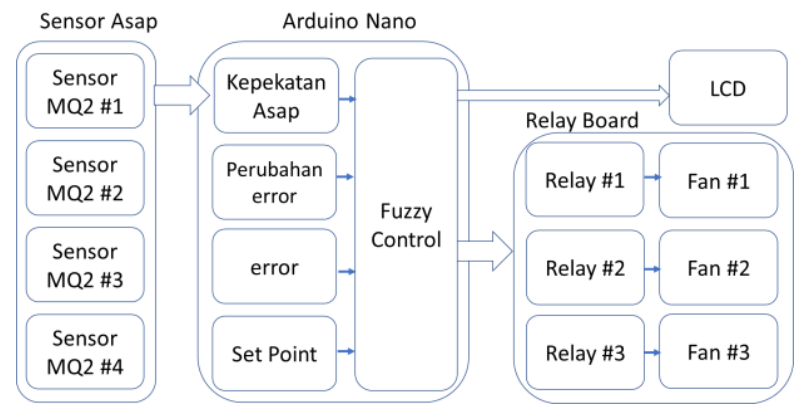

Gambar 2. Diagram Sistem Pengendali 
Procedia of Engineering and Life Science Vol. 1. No. 2 Juni 2021

Seminar Nasional \& Call Paper Fakultas Sains dan Teknologi (SENASAINS $2^{\text {nd }}$ )

Universitas Muhammadiyah Sidoarjo

Beberapa percobaan dilakukan untuk memperoleh nilai kepekatan asap. Tabel 1 berikut menyajikan nilai kepekatan asap pada rentang $60 \mathrm{ppm}$ sampai $100 \mathrm{ppm}$. Langkah selanjutnya adalah penentuan interval masing-masing variabel himpunan fuzzy ditampilkan pada tabel 1 
Procedia of Engineering and Life Science Vol. 1. No. 2 Juni 2021

Seminar Nasional \& Call Paper Fakultas Sains dan Teknologi (SENASAINS 2nd)

Universitas Muhammadiyah Sidoarjo

Tabel 1. Tabel Interval Berdasarkan Pada Variabel dalam Tiap Himpunan Fuzzy

\begin{tabular}{c|c|c|c|c}
\hline Fungsi & Nama Variabel & Nama Himpunan Fuzzy & Semesta Pembicara (unit) & Interval \\
\hline \multirow{3}{*}{ Masukkan } & \multirow{2}{*}{ Sensor_Asap } & Rendah & & {$[60-73.33]$} \\
& & Sedang & {$[60-100]$} & {$[73.33-86.66]$} \\
& Tinggi & & {$[86.66-100]$} \\
& \multirow{2}{*}{ Error } & Negatif & Zero & {$[-1-0.5]$} \\
& Positif & & {$[-0.5-1]$} \\
& Pegatif & {$[-1-1]$} & {$[0.5-1]$} \\
& Perubahan Error & Zero & {$[-1-0.5]$} \\
& & Positif & & {$[-0.5-1]$} \\
\hline
\end{tabular}

Karena sistem kendali yang digunakan adalah logika fuzzy maka kepekatan asap kemudian diberi label sebagai himpunan fuzzy. Dipilih tiga himpunan fuzzy Rendah, Sedang Tinggi.

Tabel 2. Derajat Keanggotaan Kepekatan Asap

\begin{tabular}{c|c|c|c|c|c}
\hline No & Nilai input & $\boldsymbol{\mu R e n d a h}$ & $\boldsymbol{\mu}$ Sedang & $\boldsymbol{\mu}$ Tinggi & Derajat Keangotaan \\
\hline 1 & 60 & 0 & - & - & Rendah \\
2 & 65 & 0.8 & - & - & Rendah \\
3 & 70 & 0.95 & - & - & Rendah \\
4 & 75 & 0.87 & 0.13 & - & Sedang \\
5 & 80 & 0.49 & 0.5 & - & Sedang \\
6 & 87 & - & 0.97 & - & Sedang \\
7 & 90 & - & - & -0.97 & Tinggi \\
8 & 95 & - & - & 0.62 & Tinggi \\
9 & 100 & - & - & 1 & Tinggi \\
10 & 105 & - & - & 1 & Tinggi \\
\hline
\end{tabular}

Kemudian dari tabel 2 setelah nilai input dan nilai himpunan sudah dimasukan maka bisa dibuat gambar 3 yang dimana adalah membership function variabel kepekatan asap.

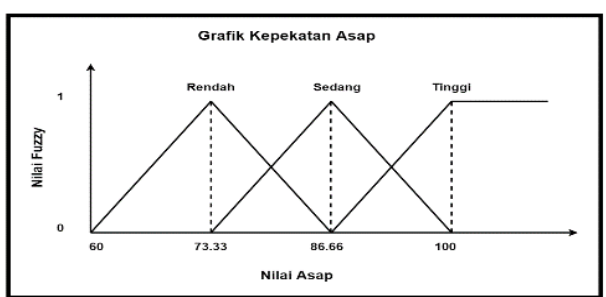

Kepekatan Asap Sedang $\mu$ Sedang(Asap) $=\left\{\begin{array}{lc}0 ; \quad \text { Asap } \leq 73.33 \text { atau Asap } \geq 100 \\ \frac{\text { Asap }-73.33}{13.33} ; & 73.33 \leq \text { Asap } \leq 86.66 \\ \frac{100-\text { Asap }}{13.34} ; & 86.66 \leq \text { Asap } \leq 100\end{array}\right\}$
Kepekatan Asap Rendah

$\mu$ Rendah (Asap) $=\left\{\begin{array}{lr}0 ; & \text { Asap } \leq 60 \text { atau Asap } \geq 86.66 \\ \frac{\text { Asap }}{73.33} & 60 \leq \text { Asap } \leq 73.33 \\ \frac{86.66-\text { Asap }}{13.33} ; & 73.33 \leq \text { Asap } \leq 86.66\end{array}\right\}$

Kepekatan Asap Tinggi

$\mu$ Tinggi(Asap) $=\left\{\begin{array}{lcc}0 ; & \text { Asap } \leq 100 \\ \text { Asap }-100 & 86.66 \leq & \text { Asap } \leq 100 \\ 13.34 & \vdots & \text { Asap } \geq 100\end{array}\right\}$

Gambar 3. Membership Function variabel kepekatan asap dan Rumus Inference Kepekatan Asap

Langkah selanjutnya dengan tabel derajat keanggotaan error yang dimana tabel ini untuk perubahan antar nilai hasil sensor terhadap set point yang diinginkan yang bisa dilihat pada tabel 3 .

Tabel 3. Derajat Keanggotaan Error

\begin{tabular}{c|c|c|c|c|c|c|c}
\hline No & Set point & Hasil sensor & Error & Perubahan Error & $\boldsymbol{\mu}$ Negatif & $\boldsymbol{\mu}$ Zero & $\boldsymbol{\mu}$ Positif \\
\hline 1 & 60 & 60 & 0 & 0 & 0 & 0 & - \\
2 & 60 & 65 & -5 & -5 & - & - & 0 \\
3 & 60 & 70 & -10 & 5 & - & - & 1 \\
\hline
\end{tabular}


Procedia of Engineering and Life Science Vol. 1. No. 2 Juni 2021

Seminar Nasional \& Call Paper Fakultas Sains dan Teknologi (SENASAINS 2nd)

Universitas Muhammadiyah Sidoarjo

\begin{tabular}{c|c|c|c|c|c|c|c}
\hline No & Set point & Hasil sensor & Error & Perubahan Error & $\boldsymbol{\mu}$ Negatif & $\boldsymbol{\mu}$ Zero & $\boldsymbol{\mu}$ Positif \\
\hline 4 & 60 & 75 & -15 & 5 & - & - & 1 \\
5 & 60 & 80 & -20 & 5 & - & - & 1 \\
6 & 60 & 87 & -27 & 7 & - & - & 1 \\
7 & 60 & 90 & -30 & 3 & - & - & 1 \\
8 & 60 & 95 & -35 & 5 & - & - & 1 \\
9 & 60 & 100 & -40 & 5 & - & - & 1 \\
10 & 60 & 105 & -45 & 5 & - & - & 1 \\
\hline
\end{tabular}

Setelah diketahui derajat keanggotaan error selanjutnya untuk representasi grafik dan rumus inference error maupun perubahan eror dijadikan kedalam satu grafik dan rumus karena memiliki nilai interval dan semesta pembicaraa yang sama. Berikut ini adalah representasi grafik dan rumus inference pada membership function eror yang disajikan pada gambar 4.
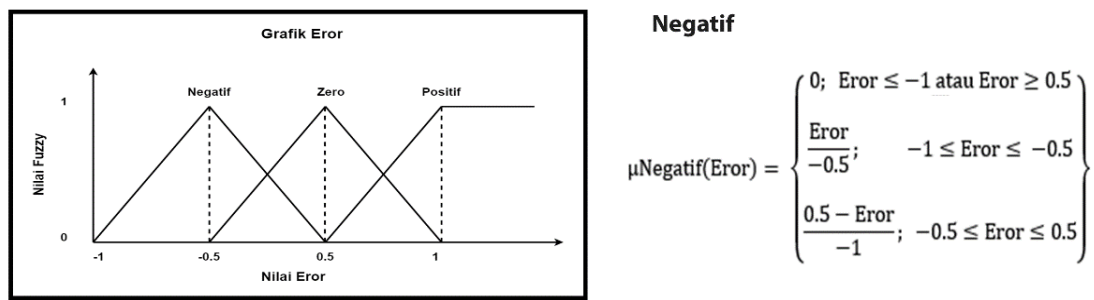

Zero

Positif

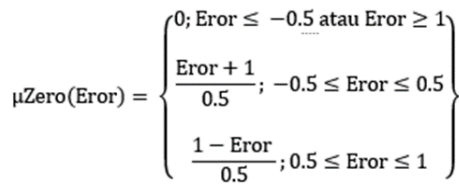

$\mu$ Positif(Eror) $=\left\{\begin{array}{lcc}0 ; & \text { Eror } \leq 1 \\ \text { Eror }-1 & \vdots \vdots & \\ \hdashline 0.5 ; & 0.5 & \text { Eror } \leq 1 \\ 1 ; & & \text { Eror } \geq 1\end{array}\right\}$

Gambar 4. Representasi Grafik dan Rumus Inference Grafik Eror

Pembentukan representasi grafik dan rumus untuk inference juga dilakukan untuk membership function perubahan eror. Berikut ini adalah representasi grafik dan rumus inference membership function perubahan eror yang disajikan dalam gambar 5:

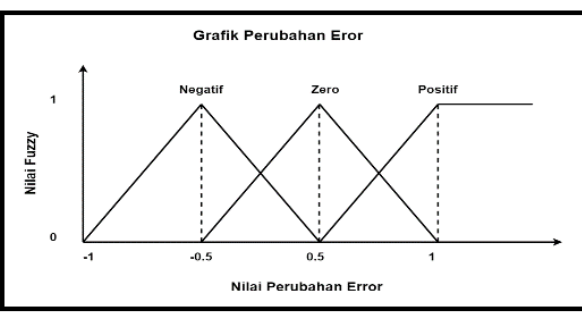

Zero

$$
\mu \text { Zero(dEror) }=\left\{\begin{array}{c}
0 ; \mathrm{dEror} \leq-0.5 \text { atau dEror } \geq 1 \\
\frac{\text { Eror }+1}{0.5} ;-0.5 \leq \mathrm{dEror} \leq 0.5 \\
\frac{1-\text { Eror }}{0.5} ; 0.5 \leq \mathrm{dEror} \leq 1
\end{array}\right\}
$$

Negatif

$$
\mu \text { Negatif(dEror })=\left\{\begin{array}{l}
\frac{0 \text {; dEror } \leq-1 \text { atau dEror } \geq 0.5}{-0.5 ;} \quad-1 \leq \text { dEror } \leq-0.5 \\
\frac{0.5-\text { Eror }}{-1} ;-0.5 \leq \text { dEror } \leq 0.5
\end{array}\right\}
$$

Positif

$$
\mu \text { Positif(Eror) }=\left\{\begin{array}{lr}
0 ; & \text { dEror } \leq 1 \\
\frac{\text { Eror }-1}{0.5} ; 0.5 \leq & \text { dEror } \leq 1 \\
1 ; & \text { dEror } \geq 1
\end{array}\right\}
$$

Representasi

Grafik dan Rumus Inference Perubahan Eror

Setelah proses penentuan semesta pembicara dan penentuan interval untuk masing-masing variabel disetiap himpunan fuzzy maka langkah selanjutnya adalah penentuan rule based. Penggunaan operator dalam rule based pada 
table 4 ini menggunakan AND karena dalam hasil pembuatan grafik representasi segitiga terdapat nilai yang berada dalam 2 grafik dan sesuai dengan bentuk umum dari Metode Sugeno. Bentuk umum dari Metode Sugeno adalah:

$$
\text { IF ( } \left.x_{1} \text { is } y_{1}\right) \text { AND...AND } x_{n} \text { is } y_{n} T H E N Z
$$

Penentuan jumlah rule based didasarkan pada jumlah himpunan fuzzy yang dibuat yaitu 3 himpunan fuzzy. Pada setiap himpunan fuzzy memiliki masing-masing 3 variabel, sehingga nilainya menjadi $3^{3}=27$ rule based [6]. Rule based yang terbentuk adalah sebagai berikut pada tabel 4 .

Tabel 4. Penentuan jumlah rule based

\begin{tabular}{|c|c|c|c|c|c|c|c|}
\hline No & \multicolumn{6}{|c|}{ Rule Based } & Status Kipas \\
\hline 1 & If & Asap $=$ Rendah & and & Eror $=$ Negatif & and & dEror $=$ Negatif & Kipas 1 Nyala \\
\hline 2 & If & Asap $=$ Rendah & and & Eror $=$ Negatif & and & $\mathrm{dEror}=$ Zero & \\
\hline 3 & If & Asap $=$ Rendah & and & Eror $=$ Negatif & and & dEror $=$ Positif & \\
\hline 4 & If & Asap $=$ Rendah & and & Eror $=$ Zero & and & $\mathrm{dEror}=$ Negatif & \\
\hline 5 & If & Asap $=$ Rendah & and & Eror $=$ Zero & and & $\mathrm{dEror}=$ Zero & \\
\hline 6 & If & Asap $=$ Rendah & and & Eror $=$ Zero & and & $\mathrm{dEror}=$ Positif & \\
\hline 7 & If & Asap $=$ Rendah & and & Eror $=$ Positif & and & dEror $=$ Negatif & \\
\hline 8 & If & Asap $=$ Rendah & and & Eror $=$ Positif & and & $\mathrm{dEror}=$ Zero & \\
\hline 9 & If & Asap $=$ Rendah & and & Eror $=$ Positif & and & $\mathrm{dEror}=$ Positif & \\
\hline 10 & If & Asap $=$ Sedang & and & Eror $=$ Negatif & and & dEror $=$ Negatif & Kipas 1 dan 2 Nyala \\
\hline 11 & If & Asap $=$ Sedang & and & Eror $=$ Negatif & and & $\mathrm{dEror}=$ Zero & \\
\hline 12 & If & Asap = Sedang & and & Eror $=$ Negatif & and & $\mathrm{dEror}=$ Positif & \\
\hline 13 & If & Asap $=$ Sedang & and & Eror $=$ Zero & and & dEror $=$ Negatif & \\
\hline 14 & If & Asap $=$ Sedang & and & Eror $=$ Zero & and & $\mathrm{dEror}=$ Zero & \\
\hline 15 & If & Asap $=$ Sedang & and & Eror $=$ Zero & and & $\mathrm{dEror}=$ Positif & \\
\hline 16 & If & Asap = Sedang & and & Eror $=$ Positif & and & dError $=$ Negatif & \\
\hline 17 & If & Asap $=$ Sedang & and & Eror $=$ Positif & and & dError $=$ Zero & \\
\hline 18 & If & Asap = Sedang & and & Eror $=$ Positif & and & dEror $=$ Positif & \\
\hline 19 & If & Asap = Tinggi & and & Eror $=$ Negatif & and & dEror $=$ Negatif & Kipas 1, 2 dan 3 Nyala \\
\hline 20 & If & Asap = Tinggi & and & Eror $=$ Negatif & and & $\mathrm{dEror}=$ Zero & \\
\hline 21 & If & Asap $=$ Tinggi & and & Eror $=$ Negatif & and & $\mathrm{dEror}=$ Positif & \\
\hline 22 & If & Asap $=$ Tinggi & and & Eror $=$ Zero & and & dError $=$ Negatif & \\
\hline 23 & If & Asap $=$ Tinggi & and & Eror $=$ Zero & and & $\mathrm{dError}=$ Zero & \\
\hline 24 & If & Asap $=$ Tinggi & and & Eror $=$ Zero & and & $\mathrm{dEror}=$ Positif & \\
\hline 25 & If & Asap $=$ Tinggi & and & Eror $=$ Positif & and & $\mathrm{dEror}=$ Negatif & \\
\hline 26 & If & Asap $=$ Tinggi & and & Eror $=$ Positif & and & $\mathrm{dEror}=$ Zero & \\
\hline 27 & If & Asap = Tinggi & and & Eror $=$ Positif & and & $\mathrm{dEror}=$ Positif & \\
\hline
\end{tabular}

Setelah penentuan rule based, langkah selanjutnya adalah inference, proses infrence adalah proses pengolahan input berupa nilai fuzzy yang didapat dari proses fuzifikasi dengan mengkombinasikan fuzzy rule base untuk memperoleh output berupa nilai fuzzy baru [3]. Proses inferencenya menggunakan metode implikasi MIN yaitu mengambil nilai terbesar derajat keanggotaan dari himpunan fuzzy dan dalam nilai fuzzy terdapat nilai negatif. Berikut ini adalah proses inference:

R1. If (Asap is Rendah) and (Eror is Negatif) and (dEror is Negatif) then Kipas1 is Nyala

$\alpha$ predikat $1=\mu$ Rendah $\cap \mu$ Negatif $\cap \mu$ Negatif

$$
\begin{aligned}
& =\max (\mu \text { Rendah }[60] \cap \mu \text { Negatif }[0] \cap \mu \text { Negatif }[0]) \\
& =\max (0 ; 0 ;-0.5) \\
& =0 ;
\end{aligned}
$$$$
\mathrm{z} 1=0 * 60+0=0
$$

R17. If (Asap is Sedang) and (Eror is Positif ) and (dEror is Positif) then

Kipas1 dan Kipas2 is Nyala

$\alpha \_$predikat $17=\mu$ Sedang $\cap \mu$ Negatif $\cap \mu$ Positif

$$
\begin{aligned}
& =\max (\mu \text { Sedang }[75] \cap \mu \text { Negatif }[5] \cap \mu \text { Positif[5]) } \\
& =\max (0,13 ; 1 ; 1) \\
& =1 \text {; } \\
& \mathrm{z} 17=1 *(75+1+1)+(1+1)=79
\end{aligned}
$$

R27. If (Asap is Tinggi) and (Eror is Positif) and (dEror is Positif) then

Kipas1+kipas2+kipas3 is Nyala

$\alpha \_$predikat27 $=\mu$ Tinggi $\cap \mu$ Negatif $\cap \mu$ Positif 


$$
\begin{aligned}
= & \max (\mu \text { Tinggi }[95] \cap \mu \text { Negatif }[] \cap \mu \text { Positif }[35]) \\
& =\max (0.62 ; 1 ; 1) \\
& =1 ; \\
\mathrm{z} 27=1 *(95+1+1)+(1+1+1) & =100
\end{aligned}
$$

Langkah berikutnya adalah proses defuzzifikasi, yaitu langkah terakhir dalam suatu sistem logika fuzzy dimana tujuannya adalah mengkonversi setiap hasil dari inference engine yang diekspresikan dalam bentuk fuzzy set ke suatu bilangan real. Hasil defuzzifikasi Metode Sugeno menggunakan rumus weight-average sehingga hasilnya adalah :

$$
\begin{aligned}
& \mathrm{Z}=\frac{\propto_{\text {predikat } 1} * z 1+\cdots+\propto_{\text {predikat } 12} * z 12+\ldots+\propto_{\text {predikat } 27} * z 27}{z 1+\cdots+z 12+\cdots+z 27} \\
& \mathrm{Z}=\frac{0 * 0+\cdots+1 * 79+\cdots+1 * 100}{\mathrm{Z}=125.82}
\end{aligned}
$$

Sehingga, dari perhitungan defuzifikasi dengan menggunakan metode weight-average menghasilkan nilai himpunan tegas $=125.82$

\section{B. Hasil uji coba}

Berikut hasil uji coba pengujian kepekatan asap yang disertakan dalam tabel 1. Hasil pengujian ini menghasilkan 3 kategori kepekatan asap Rendah, Sedang,Tinggi. Dimana percobaan ini dilakukan dengan memasukkan asap bakaran dari kertas ke dalam kotak percobaan selama 10 menit. Nilai titik terendah yang dimulai adalah 60 ppm hingga titik tertinggi 100 ppm. Hasil uji coba ini juga ditampilkan dalam LCD berukuran 20x4 yang ada pada gambar 6 . Apabila nilai < 60 ppm maka secara otomatis akan menghasilkan kepekatan asap sangat rendah seperti pada gambar 6a.

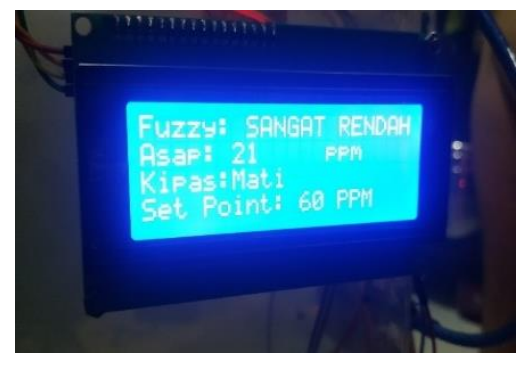

(a)

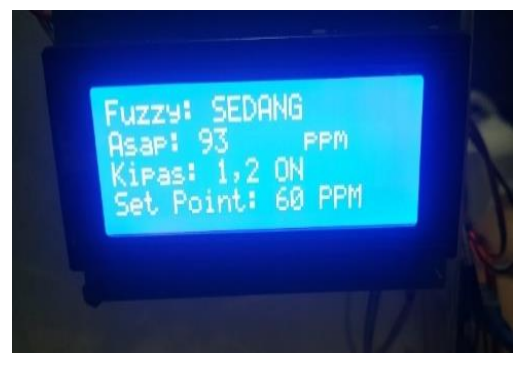

(b)

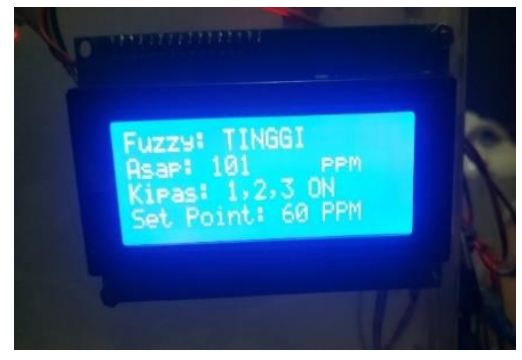

(c)

Gambar 6. (a) Nilai asap $<60$ ppm (b) Nilai asap $>70$ ppm dan $<95$ ppm

(c) Nilai Asap> $100 \mathrm{ppm}$

Apabila nilai $>70$ ppm dan $<95$ ppm maka secara otomatis akan menghasilkan kepekatan asap sedang seperti pada gambar 6b, apabila nilai > 100 ppm maka secara otomatis akan menghasilkan kepekatan asap sedang seperti pada gambar 6c. Selain pengujian kepekatan asap, pengujian kecepatan waktu kipas dalam mengeluarkan asap juga dilakukan, sehingga menghasilkan waktu pada tabel 5.

Tabel 5. Hasil percobaan waktu

\begin{tabular}{c|c|c}
\hline No. & Kondisi kepekatan asap & Waktu \\
\hline 1 & Tinggi-Sedang & $\pm 475.3 \mathrm{~ms}$ \\
2 & Tinggi-Nilai setpoint $(60 \mathrm{ppm})$ & $\pm 483.5 \mathrm{~ms}$ \\
\hline
\end{tabular}




\section{KESIMPULAN}

Hasil pengujian kepekatan asap dan nyala kipas sebagai output yang dilakukan selama 10 menit untuk pengambilan nilai sampel asap dengan penentuan nilai setpoint sebesar $60 \mathrm{ppm}$, maka didapatkan hasil kipas yang menyala sudah sesuai dengan tingkat kepekatan asap yaitu : Kepekatan Asap rendah dengan kipas menyala 1 buah, Kepekatan Asap sedang dengan kipas menyala 2 buah dan Kepekatan Asap tinggi dengan kipas menyala 3 buah. Selain pengujian dengan kepekatan asap, hasil pengujian waktu dalam mengeluarkan asap dari kepekatan asap tinggi hingga ketitik nilai setpoint yang sudah ditentukan yaitu sebesar 60 ppm, maka didapatkan waktu 483,65ms.

\section{REFERENSI}

[1] Effendy, F,A,. 2015.Kendali Kecepatan Kipas Pembuangan Pada Ruang Khusus Merokok Sebagai Pembersih Dan Pengatur Sirkulasi Udara Berbasis Mikrokontroller, Skripsi Strata 1 Teknik Elektro, Universitas Telkom Bandung.

[2] Iwan Supriyatna. 2017 "Percuma Jalani Pola Hidup Sehat Kalau Masih Merokok". https://lifestyle.kompas.com/read/2017/07/19/170900120/percuma-jalani-pola-hidup-sehat-kalau-masihmerokok. Diakses pada 24 Februari 2020.

[3] Kusumadewi, S., dan Purnomo, S. 2010. Aplikasi Logika Fuzzy untuk Pendukung Keputusan. Penerbit : Graha Ilmu. Yogyakarta.

[4] M. Passino, Kevin, Yurkovich, Stephen, Fuzzy Control, Addison-Wesley Longman Inc., California, 1998.

[5] Nebath, E., 2014. Rancang Bangun Alat Pengukur Gas Berbahaya CO Dan CO2 di Lingkungan Industri. EJournal Teknik Elektro dan Komputer, pp. 2301-8402 .

[6] Novriyenni \& Diky Hamdani (2017). Implementasi Motode Fuzzy Sugeno pada Pengendalian Exhoust Fan Sebagai Pembersih dan Pengatur Udara. Jurnal MEANS (Media Informasi Analisa dan Sistem), 2(2), 88 - 92.

[7] Organisasi Kesehatan Dunia (2020). "Constitution of the World Health Organization". Basic Documents (PDF) (edisi ke-49). Jenewa: Organisasi Kesehatan Dunia. hlm. 1. ISBN 978-92-4-000051-3.

[8] Peraturan Menteri Tenaga Kerja Dan Transmigrasi Republik Indonesia Nomor 13/MEN/X/2011 tentang Nilai Ambang Batas (NAB) Faktor Fisika dan Faktor Kimia Hal 1-40.

[9] T.Sutojo,T, dkk. 2011.Kecerdasan Buatan. Yogyakarta: CV.Andi OFFSET.

[10] Utomo, B, T, Wahjo dan Saputra, D, Setya. 2016. Simulasi Sistem Pendeteksi Polusi Ruangan Menggunakan Sensor Asap Dengan Pemberitahuan Melalui SMS (Short Message Service ) Dan Alarm Berbasis Arduino. Jurnal Ilmiah Teknologi dan Informasia ASIA (JITIKA) Vol.10, No.1, Februari 2016 ISSN: 0852-730X 